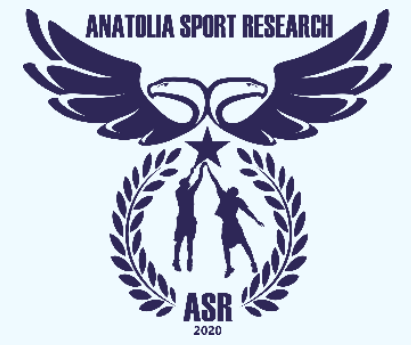

ANATOLIA SPORT RESEARCH

\author{
ISSN: 2757-6485
}

$2021 \& 2$ (3)

\title{
Tokyo 2020 Yaz Olimpiyat Oyunlarındaki Kurbağalama Yüzme Derecelerinin Analizi
}

\author{
"Analysis of Breaststroke Swimming Degrees at the Tokyo 2020 Summer Olympic \\ Games"
}

\author{
Gökçe AKGÜN ${ }^{1}$
}

\section{ARASTTIRMA MAKALESI}

\section{Tarihçe}

Yayın Geliş Tarihi: 25 Ağustos 2021

Kabul Tarihi: 3 Kasım 2021

Online Yayın Tarihi: 30 Aralık 2021

DOI: $\underline{\text { http://dx.doi.org/10.29228/anatoliasr.19 }}$

\section{Yazarlarla İletişim}

1- (Sorumlu Yazar) İstanbul Üniversitesi Cerrahpaşa, Lisansüstü Eğitim Enstitüsü, Hareket ve Antrenman Bilimleri Doktora Programı, İstanbul, TÜRKIYE

gokce.akgun@ogr.iuc.edu.tr

https://orcid.org/0000-0001-9487-6932

\section{Yazar Katkıları}

Tüm yazarlar çalışmanın konseptine ve tasarımına katkıda bulundu.

\section{Finansman}

$\mathrm{Bu}$ çalışma herhangi bir kurum/kuruluştan maddi destek almadi.

\section{Çıkar Çatışması}

Yazarlar çıkar çatışması olmadığını beyan ediyorlar.

\section{Şeffaflık}

Yazarlar, çalışmada hiçbir hayati özelliğin ihmal edilmediğini, dürüst, doğru ve şeffaf bir anlatım ile raporlaştırıldığını ve herhangi bir tutarsızlık olmadığını beyan etmişlerdir.

\section{Etik}

$\mathrm{Bu}$ çalışmada bilimsel etik kriterlerine uyulmuştur.

\section{Referans Gösterimi}

Akgün, G. (2021). Tokyo 2020 Yaz Olimpiyat Oyunlarındaki Kurbağalama Yüzme Derecelerinin Analizi, Anatolia Sport Research, 2(3): 30-38.

Copyright (C) 2021 by Anatolia Sport Research

\section{ÖZET}

Amaç: Bu çalışmanın amacı, Tokyo 2020 Yaz Olimpiyat Oyunlarında kurbağalama yüzme branşında yarışan sporcuların olimpiyata katılma hakkı elde ettikleri yüzme dereceleri ile olimpiyatlardaki eleme, yarı final ve final performanslarının karşılaştırılmasıdır.

Materyal ve Metod: Tokyo 2020'ye kurbağalama branşında katılan tüm sporcuların performansları yüzme derecelerine göre analiz edilmiştir. Tokyo 2020 Yaz Olimpiyat Oyunları'nda yüzülen kadınlar ve erkekler $100 \mathrm{~m}$ ile $200 \mathrm{~m}$ kurbağalama yarışmalarına ait resmi sporcu bilgileri temin edilmiştir. Yüzücülerin katılma hakk1 elde ettikleri yüzme dereceleri ülkelere, kıtalara ve yarışma yıllarına göre listelenmiştir. Yüzücülerin olimpiyata katılma hakkı dereceleri ile yarışma sonuçları eleme, yarı final ve final olmak üzere her kategoride 3 grupta istatistiksel olarak incelenmiştir. Katılma hakkı dereceleri ile yarışma performanslarına göre oluşan saniye farkı cinsiyet değişkenine göre hem $100 \mathrm{~m}$ hem de $200 \mathrm{~m}$ kurbağalama yüzmede incelenmiştir.

Bulgular: Olimpiyata katılma hakkı dereceleri ile yarışma sonuçları karşılaştırıldığında $100 \mathrm{~m}$ kurbağalama eleme, yarı final ve erkekler final sonuçlarında anlamlı fark olduğu bulunmuştur. Kurbağalama yüzme 200 metrede ise sadece eleme ve erkekler yarı finalinde anlamlı fark bulunmuştur. Yapılan diğer analizlerde yüzme derecelerinin istatistiksel olarak benzerlik gösterdiği görülmüştür.

Sonuç: Tokyo $2020100 \mathrm{~m}$ ve $200 \mathrm{~m}$ kurbağalama yüzme elemelerinde sporcuların olimpiyata katılma hakkı derecelerinden anlamlı düzeyde daha yavaş yüzdüğü görülmüştür. $100 \mathrm{~m}$ ve $200 \mathrm{~m}$ final aşamalarında ise sporcuların olimpiyata katılma hakkı derecelerine benzer hızda yüzdüğü anlaşılmıştır. Cinsiyet değişkenine göre Tokyo 2020 kurbağalama branşında, yüzücülerin olimpiyata katılma hakkı dereceleri ile olimpiyat yarışma sonucu dereceleri arasındaki hız farkının benzer olduğu görülmüsstür.

Anahtar Kelimeler: Kurbağalama, Olimpiyat, Tokyo 2020, Yüzme.

\section{ABSTRACT}

Aim: The aim of this study is to compare the swimming degrees of the athletes competing in the breaststroke swimming branch in the Tokyo 2020 Olympic Games, and the qualification, semi-final, and final performances in the Olympics.

Material and Method: The performances of all athletes participating in the breaststroke branch of the Tokyo 2020 were analyzed according to their swimming degrees. Official athlete information regarding the $100 \mathrm{~m}$ and $200 \mathrm{~m}$ breaststroke competitions for men and women swimming in the Tokyo 2020 Summer Olympic Games has been provided. The swimming degrees in which the swimmers have the right to participate are listed according to the countries, continents, and competition years. The degrees of the swimmers' right to participate in the Olympics and the results of the competition were statistically analyzed in 3 groups in each category: qualification, semi-final and final. The seconds' difference between the right to participate and competition performances were examined in both $100 \mathrm{~m}$ and $200 \mathrm{~m}$ breaststroke swimming according to the gender variable.

Results: When the degrees of right to participate in the Olympics were compared with the results of the competition, it was found that there was a significant difference in the $100 \mathrm{~m}$ breaststroke qualifying, semifinals and men's final. In the breaststroke swimming $200 \mathrm{~m}$, only in the qualifications and men's semi-finals were found to be significant. In other analyzes, it was seen that the swimming degrees were statistically similar. Conclussions: In the Tokyo $2020100 \mathrm{~m}$ and $200 \mathrm{~m}$ breaststroke swimming qualifications, it was observed that the athletes swam significantly slower than their right to participate in the Olympics. In the $100 \mathrm{~m}$ and 200 $\mathrm{m}$ final stages, it was understood that the athletes swam at a speed similar to their right to participate in the Olympics. According to the gender variable, in the breaststroke branch of the Tokyo 2020, the difference in speed between the swimmers' right to participate in the Olympics and the results of the Olympic competition was similar.

Keywords: Breaststroke, Olympic, Swimming, Tokyo 2020. 


\section{GíRiş}

Yüzme insan yaşamında büyük öneme sahiptir. Tarihsel süreçte spor branşlarının gelişmesiyle yüzme de bu branşlar arasında yer almış ve sportif anlamda yaygın olarak yapılabilir bir dal haline gelmiştir. Ulusal ve uluslararası çoğu spor yarışması ve etkinliğinde yüzme branşının yer aldığı görülmüştür (FINA, 2017; Tokyo, 2020). Yüzme, 1896 yılında yapılan ilk modern olimpiyat oyunlarında yer alan spor branşlarından biri olmuştur (Hołub et al., 2021). Yüzme stilleri ve teknik özellikleri zamanla gelişerek günümüzdeki halini almıştır. Dönem dönem yarışmalara pek çok yüzme disiplini ve kategorisi eklenmiştir. Kurbağalama yüzme teknik açıdan simetrik yapıda olup yüzüş sırasında aynı hareket kalıbının tekrarlı biçimde uygulanmasıyla gerçekleşmektedir (Jaszczak, 2011; Scurati et al., 2019).

Yüzme yarışmaları serbest, sırtüstü, kurbağalama ve kelebek yüzme olmak üzere 4 temel stilden oluşmaktadır. Yarışmalarda ana hedef önceden belirlenmiş mesafenin doğru teknik kullanılarak en hızlı şekilde yüzülmesidir (FINA, 2017; Tokyo, 2020). Sporcuların yaş ve cinsiyet özelliklerine göre yarışmalarda yüzdükleri mesafe derecelerinde farklı hedefler bulunmaktadır (FINA, 2017). Ayrıca her yüzme stili teknik açıdan bazı özel unsurlara sahip olduğu için belirli bir hız özelliği vardır. Teknik özellikleri açısından dört yüzme stili hızlıdan yavaşa doğru sıralandığında serbest, kelebek, sırtüstü ve kurbağalama şeklindedir. Yarışmalar için belirlenen katılım baraj dereceleri yüzme stillerinin teknik özelliklerden kaynaklanan hıza göre belirlenmektedir (FINA, 2017; FINA, 2020; Tokyo, 2020; Hołub et al., 2021).

Olimpiyat Oyunlarında kurbağalama, kelebek ve sırtüstü yüzme yarışmaları hem kadınlar hem de erkeklerde sadece 100 m ve 200 m olarak yapılmaktadır (FINA, 2017; FINA, 2020; Tokyo 2020; Hołub et al., 2021). Tarihsel açıdan kurbağalama yüzmenin 100 m mesafesi kadınlar ve erkeklerde ilk defa 1968 Meksiko Olimpiyat Oyunlarında, 200 m mesafesi erkeklerde ilk defa 1908 Londra, kadınlarda ise ilk defa 1924 Los Angeles Olimpiyat Oyunlarında yer almıştır (Hołub et al., 2021). Kurbağalama yüzmenin olimpiyat oyunlarındaki rekorları kadınlar 100 metrede 1:04.93 saniye (2016) ve 200 metrede 2:19.59 saniye (2012), erkekler 100 metrede 57.13 saniye (2016) ve 200 metrede 2:07.22 saniyedir (2016) (FINA, 2017; Tokyo 2020).

Kurbağalama yüzme aşamaları video analizlerle suyun dışından ve su altından analiz edilmektedir. Sporcuların bir kurbağalama yüzme döngüsü veya belirlenen mesafe süresince tüm yüzüş biçimi hem teknik açıdan hem de süre-hız bakımından analiz edilmektedir. Ayrıca sporcuların kurbağalama stilinin cinsiyet değişkeni ve yaş faktörü bakımından da incelendiği çalışmalar vardır. Yaş grupları ile cinsiyet ilişkisi yüzme branşlarında önem taşımaktadır (Strzała et al., 2014). İsviçre Yüzme Federasyonu'nun yarışma sonuçları üzerine yapılan bir çalışmada kadın ve erkek sporcular yüzme mesafesi ile yaş faktörüne göre karşılaştırılmıştır. Yapılan araştırmada ulusal seviyedeki İsviçreli yüzücüler ile aynı branş ve mesafedeki FINA dünya şampiyonası finalistlerinin dereceleri karşılaştırılmıştır. Yarışma sonuçlarının $50 \mathrm{~m}, 100 \mathrm{~m}$ ve $200 \mathrm{~m}$ kurbağalama yüzme mesafelerine göre istatistiksel açıdan analiz edildiği ifade edilmiş̧tir (Wolfrum et al., 2013). Abe ve arkadaşları kısa mesafe kurbağalama yüzme performansı ile kritik hız özelliği arasındaki ilişkiyi incelemişlerdir (Abe et al., 2006). Kurbağalama yüzmede ileriye uzama veya kolların içeri süpürüş ile toparlanma aşamaları olarak ifade edilen faz ile ilgili biyomekanik analizler yapılmaktadır. Yüzücüler su altı video kameraların kullanılmasıyla detaylı şekilde teknik açıdan incelenebilmektedir (Mason et al., 1989). Hołub ve arkadaşları, Olimpiyat Oyunları yüzme tarihindeki kurbağalama yüzme ve kelebek yüzme derecelerinin incelenerek Tokyo 2020 Yaz Olimpiyat Oyunlarında yüzülecek aynı branş derecelerinin tahmin edilmesine yönelik bir çalışma yapmıştır. Bu kapsamda olimpiyat oyunlarında finalde yarışmış sporcuların yüzme dereceleri incelenmiştir (Hołub et al., 2021). 
Çalışmada sporcuların Olimpiyat Oyunlarına katılma hakkı elde ettiği yüzme dereceleri ile olimpiyatlarda yüzdükleri derecelerin karşılaştırılması hedeflenmiştir. Tokyo 2020 Yaz Olimpiyat Oyunları'na kurbağalama yüzme branşında katılan sporcu performansları analiz edilmiştir. Katılma hakkı elde ettikleri yıla ve yüzme derecesine göre sporcuların olimpiyatlardaki performans durumu belirlenmiştir. 2024 yılında yapılması planlanan bir sonraki Yaz Olimpiyat Oyunlarına katılacak sporcuların kurbağalama yüzme yarışmalarına hazırlanmasında Tokyo 2020 Yaz Olimpiyat Oyunlarındaki sporcuların eleme, yarı final ve final performanslarının takibi önem taşımaktadır. Kurbağalama stil yüzücülerin Olimpiyat Oyunları gibi büyük yarışmalara hazırlanmasında önceki yarışmaların incelenmesi ve gerekli stratejilerin belirlenmesi için çalışmamızın incelenebilir niteliğe sahip olduğu düşünülmektedir. Bu çalışmanın amacı, kurbağalama yüzme branşında Tokyo 2020 Olimpiyat Oyunlarına katılma hakkı elde eden sporcuların olimpiyatlardaki eleme, yarı final ve final performanslarının yarışma dereceleri açısından incelenmesidir.

\section{MATERYAL VE METOD}

\section{Araștırma Yöntemi}

Araştırma nicel yöntem kullanılarak tekil tarama modeline göre hazırlanmıştır. Tekil tarama modelinde tek tür veya miktar olarak değişkenlerin belirlenmesine yönelik araştırmaların yapıldığı ifade edilmektedir (Karasar, 2020). Bu modele göre, Tokyo 2020 Yaz Olimpiyat Oyunları'ndaki kurbağalama yüzme yarışmaları incelenmiştir (FINA, 2020; Tokyo 2020).

\section{Araştıma Grubu}

Araştırma grubunu Tokyo 2020 Yaz Olimpiyat Oyunları'ndaki kurbağalama yüzme yarıșmalarına katılan sporcular oluşturmuştur (Tokyo 2020). Sporcuların yarışma sonuçları, Olimpiyat Oyunlarındaki dört kurbağalama yüzme yarışması olan $100 \mathrm{~m}$ kadınlar, $100 \mathrm{~m}$ erkekler, $200 \mathrm{~m}$ kadınlar ve $200 \mathrm{~m}$ erkekler şeklinde 4 grupta incelenmiştir.

\section{Veri Toplama Araçları}

Sporcuların kurbağalama yüzme dereceleri Tokyo 2020 Yaz Olimpiyat Oyunları'nın resmi yarışma sonuçlarından temin edilmiştir. Yarışma sonuçları istatistiksel açıdan analiz edilerek eleme, yarı final ve final olmak üzere her kategori 3 grupta incelenmiştir (FINA, 2020; Tokyo, 2020).

\section{Verilerin İstatistiksel Analizi}

Katılma hakkı dereceleri ile yarışma derecelerindeki azalma ve artışlar belirlenerek hem kadın hem de erkek sporcuların performansları eleme, yarı final ve final alt gruplarında analiz edilmiştir. $\mathrm{Bu}$ analizler için Mann Whitney U testi kullanılmıştır. Yarışma performanslarına göre oluşan saniye farkının cinsiyet değişkenine göre incelenmesi hem $100 \mathrm{~m}$ hem de $200 \mathrm{~m}$ kurbağalama yüzme için uygulanmıştır. Veriler normal dağılım göstermediği için parametrik olmayan testler kullanılmıştır. Sporcuların katılım dereceleri ile olimpiyat yarışma derecelerinin karşılaştırılmasında Wilcoxon İşaretli Sıralar Testi uygulanmıştır. Sporcuların yarışma sonuçları incelenirken diskalifiye olan veya katılım göstermeyenler istatistiksel analizlere dahil edilmemiştir. Bu sporcular sadece katılım hakkı olan ülkeler dağılımında yer almıştır. Hazırlanan istatistiksel analizlerde SPSS 26.0 paket programı kullanılmış, anlamlılık düzeyi $\mathrm{p}<0.05$ olacak şekilde kontrol edilmiştir. 


\section{BULGULAR}

Tokyo 2020 Yaz Olimpiyat Oyunları'na kadınlar 100 m kurbağalama yüzmede A barajını geçen 28 sporcu, B barajını geçen 6 sporcu ve baraj geçemeyip ülke katılımı hakkıyla dahil olan 13 sporcu katılmıştır. Toplam 40 ülke kadınlar $100 \mathrm{~m}$ kurbağalama yüzmede yarışmıştır. Bu ülkelerden 7 tanesi A barajını geçen 2 sporcuyla temsil edilmiştir. Tokyo 2020 Yaz Olimpiyat Oyunları'na kadınlar $200 \mathrm{~m}$ kurbağalama yüzmede A barajını geçen 26 sporcu, B barajını geçen 5 sporcu ve baraj geçemeyip ülke katılımı hakkıyla dahil olan 1 sporcu katılmıştır. Toplam 24 ülke kadınlar $200 \mathrm{~m}$ kurbağalama yüzmede yarışmıştır. Bu ülkelerden 8 tanesi A barajını geçen 2 sporcuyla temsil edilmiştir.

Tokyo 2020 Yaz Olimpiyat Oyunları'na erkekler 100 m kurbağalama yüzmede A barajını geçen 33 sporcu, B barajını geçen 9 sporcu ve baraj geçemeyip ülke katılımı hakkıyla dahil olan 7 sporcu katılmıştır. Toplam 38 ülke erkekler 100 m kurbağalama yüzmede yarışmıştır. Bu ülkelerden 11 tanesi A barajını geçen 2 sporcuyla temsil edilmiştir. Tokyo 2020 Yaz Olimpiyat Oyunları'na erkekler $200 \mathrm{~m}$ kurbağalama yüzmede A barajını geçen 25 sporcu, B barajını geçen 6 sporcu ve baraj geçemeyip ülke katılımı hakkıyla dahil olan 9 sporcu katılmıştır. Toplam 34 ülke erkekler 200 m kurbağalama yüzmede yarışmıştır. Bu ülkelerden 6 tanesi A barajını geçen 2 sporcuyla temsil edilmiştir.

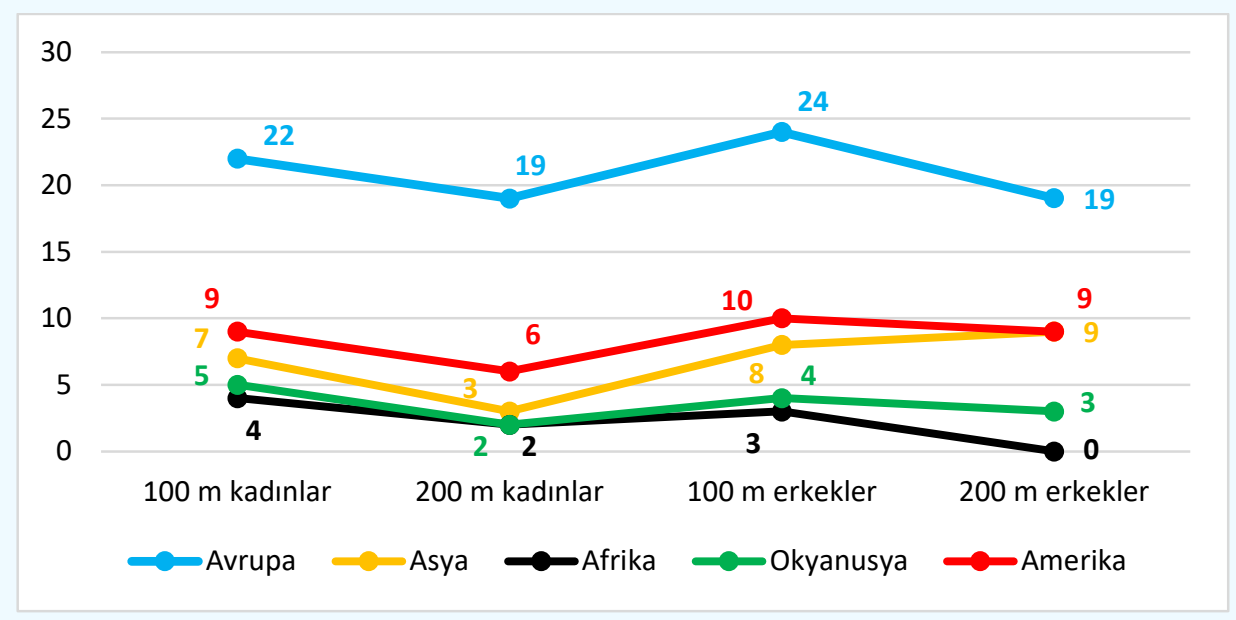

Figür 1. Kıta’lara göre kurbağalama yüzme kategorilerinde yer alan sporcuların dağılımı

Figür 1 incelendiğinde, kurbağalama yüzmede Tokyo 2020 Yaz Olimpiyat Oyunlarına katılma hakkı elde eden sporcuların yarışma türüne ve kıtalara göre dağılımının yer aldığı görülmektedir. Figür 1'de yer alan sayısal dağılımlara göre, Tokyo 2020 Olimpiyat Oyunları'nda kurbağalama yüzme kategorilerinde en çok katılım Avrupa kıtasından, en az katılım ise Afrika kıtasından sağlanmıştır.

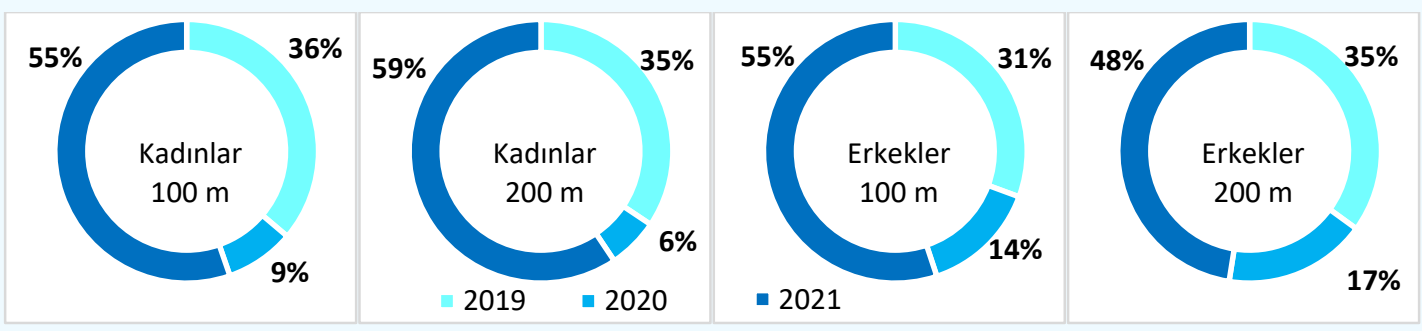

Figür 2. Sporcuların olimpiyatlara katılım hakkı elde ettikleri yıllara göre dağılımı 
Figür 2 incelendiğinde, sporcuların Tokyo 2020 Olimpiyat Oyunları'na katılma hakkı elde ettikleri yılların dağılımı cinsiyet ve kategorilere göre yer almaktadır. Dağılıma göre, katılım hakkı kazanan sporcuların sayıca en yüksek olduğu yıl 2021 olarak tespit edilmiştir (Figür 2).

Tokyo 2020 Yaz Olimpiyat Oyunları'nda kurbağalama yüzme yarışmalarında 2 sporcuyla temsil edilen ülkelerin eleme, yarı final ve finaldeki sayısal dağılımının aşağıdaki şekilde olduğu görülmüştür:

- Kadınlar 100 m elemede 2'şer sporcuyla temsil edilen ülke sayısı 7, yarı finalde 2 ve finalde 2 olmuştur.

- Kadınlar 200 m elemede 2'şer sporcuyla temsil edilen ülke sayısı 8, yarı finalde 4 ve finalde 3 olmuştur.

- Erkekler 100 m elemede 2'şer sporcuyla temsil edilen ülke sayısı 11, yarı finalde 5 ve finalde 2 olmuştur.

- Erkekler 200 m elemede 2'şer sporcuyla temsil edilen ülke sayısı 6, yarı finalde 4 ve finalde ülkeler 1'er sporcuyla temsil edilmiştir.

Tablo 1. Tokyo 2020 kurbağalama yüzme sporcu sayllarl ve ortalama yüzme dereceleri

\begin{tabular}{cllccc}
\hline \multirow{2}{*}{$\begin{array}{c}\text { Yarışma } \\
\text { mesafesi }\end{array}$} & Yarışma aşaması & \multicolumn{2}{c}{ Kadınlar } & \multicolumn{2}{c}{ Erkekler } \\
\cline { 2 - 6 } & & Ortalama derece & Sporcu sayıs1 & Ortalama derece & Sporcu sayıs1 \\
\hline \multirow{2}{*}{$\mathbf{1 0 0} \mathbf{~ m}$} & Eleme & $1: 09: 88$ & $43(47)^{*}$ & $1: 00: 52$ & $47(49)^{*}$ \\
\cline { 2 - 6 } & Yarı final & $1: 06: 54$ & 16 & $59: 15$ & 16 \\
\cline { 2 - 6 } & Final & $1: 05: 85$ & 8 & $58: 61$ & 8 \\
\hline \multirow{2}{*}{$\mathbf{2 0 0} \mathbf{m}$} & Eleme & $2: 25: 02$ & $31(32)^{*}$ & $2: 11: 92$ & $39(40)^{*}$ \\
\cline { 2 - 6 } & Yarı final & $2: 23: 37$ & $15(16)^{*}$ & $2: 08: 95$ & 16 \\
\cline { 2 - 6 } & Final & $2: 21: 70$ & 8 & $2: 07: 65$ & 8 \\
\hline
\end{tabular}

*: Diskalifiye olan sporcu bulunmaktadır.

Tablo 1 incelendiğinde, Tokyo 2020 kurbağalama yüzme yarışma aşamalarının ortalama yüzme dereceleri bulunmaktadır. Yarışmalarda diskalifiye olan sporcuların yüzme dereceleri ortalama hesaplamalarına dahil edilmemiştir.

Tablo 2. Yüzücülerin $100 \mathrm{~m}$ katılma hakkı dereceleri ile olimpiyat yarışma sonuçlarının karşılaştırması

\begin{tabular}{|c|c|c|c|c|c|c|c|c|c|c|}
\hline \multirow[b]{2}{*}{ Değişken } & \multicolumn{5}{|c|}{ Kadınlar } & \multicolumn{5}{|c|}{ Erkekler } \\
\hline & $\mathbf{n}$ & $\begin{array}{l}\text { Sira } \\
\text { ort. }\end{array}$ & $\begin{array}{c}\text { Siralar } \\
\text { top. }\end{array}$ & $\mathbf{Z}$ & $\mathbf{p}$ & $\mathbf{n}$ & $\begin{array}{l}\text { Sira } \\
\text { ort. }\end{array}$ & $\begin{array}{c}\text { Siralar } \\
\text { top. }\end{array}$ & $\mathbf{Z}$ & $\mathbf{p}$ \\
\hline \multicolumn{11}{|c|}{100 m kurbağalama yüzme eleme } \\
\hline Negatif siralar & 13 & 18,38 & 239,00 & \multirow{3}{*}{$-2,826$} & \multirow{3}{*}{0,005} & 10 & 12,70 & 127,00 & \multirow{3}{*}{$-4,625$} & \multirow{3}{*}{0,000} \\
\hline Pozitif sıralar & 30 & 23,57 & 707,00 & & & 37 & 27,05 & 1001,00 & & \\
\hline Eşit & 0 & & & & & 0 & & & & \\
\hline \multicolumn{11}{|c|}{100 m kurbağalama yüzme yarı final } \\
\hline Negatif siralar & 2 & 3,00 & 6,00 & \multirow{3}{*}{$-3,206$} & \multirow{3}{*}{0,001} & 2 & 2,50 & 5,00 & \multirow{3}{*}{$-3,259$} & \multirow{3}{*}{0,001} \\
\hline Pozitif sıralar & 14 & 9,29 & 130,00 & & & 14 & 9,36 & 131,00 & & \\
\hline Eşit & 0 & & & & & 0 & & & & \\
\hline \multicolumn{11}{|c|}{100 m kurbağalama yüzme final } \\
\hline Negatif siralar & 3 & 2,83 & 8,50 & \multirow{3}{*}{$-1,332$} & \multirow{3}{*}{0,183} & 1 & 2,00 & 2,00 & \multirow{3}{*}{$-2,240$} & \multirow{3}{*}{0,025} \\
\hline Pozitif sıralar & 5 & 5,50 & 27,50 & & & 7 & 4,86 & 34,00 & & \\
\hline Eşit & 0 & & & & & 0 & & & & \\
\hline
\end{tabular}

Tablo 2 incelendiğinde kadınlar ve erkekler 100 m kurbağalama yüzme yarışma sonuçları ile aynı sporcuların olimpiyat oyunlarına katılma hakkı kazandığı dereceleri istatistiksel olarak analiz edilmiştir. Hem eleme hem de yarı final derecelerine bakıldığında aynı sporcuların yüzme dereceleri arasında anlamlı farkın olduğu anlaşılmıştır $(\mathrm{p}<0.01)$. Ayrıca erkekler $100 \mathrm{~m}$ finalinde de farkın düşük düzeyde anlamlı olduğu belirlenmiştir $(\mathrm{p}<0.05)$. Analizlere göre çıkan anlamlı farkların sporcuların katılma hakkı 
derecelerinden daha yavaş yüzdükleri için oluştuğu anlaşılmıştır. Kadınlar $100 \mathrm{~m}$ finalinde yüzme derecelerinin benzer olduğu anlaşılmıştır ( $\mathrm{p}>0.05)$.

Tablo 3. Yüzücülerin $200 \mathrm{~m}$ katılma hakkı dereceleri ile olimpiyat yarışma sonuçlarının karşılaştırması

\begin{tabular}{|c|c|c|c|c|c|c|c|c|c|c|}
\hline \multirow[b]{2}{*}{ Değişken } & \multicolumn{5}{|c|}{ Kadınlar } & \multicolumn{5}{|c|}{ Erkekler } \\
\hline & $\mathbf{n}$ & $\begin{array}{l}\text { Sira } \\
\text { ort. }\end{array}$ & $\begin{array}{c}\text { Siralar } \\
\text { top. }\end{array}$ & $\mathbf{Z}$ & $\mathbf{p}$ & $\mathbf{n}$ & $\begin{array}{l}\text { Sira } \\
\text { ort. }\end{array}$ & $\begin{array}{c}\text { Siralar } \\
\text { top. }\end{array}$ & $\mathbf{Z}$ & $\mathbf{p}$ \\
\hline \multicolumn{11}{|c|}{200 m kurbağalama yüzme eleme } \\
\hline Negatif siralar & 6 & 13.25 & 79.50 & \multirow{3}{*}{-3.302} & \multirow{3}{*}{0.001} & 6 & 14.00 & 84.00 & \multirow{3}{*}{-4.270} & \multirow{3}{*}{0.000} \\
\hline Pozitif sıralar & 25 & 16.66 & 416.50 & & & 33 & 21.09 & 696.00 & & \\
\hline Eşit & 0 & & & & & 0 & & & & \\
\hline \multicolumn{11}{|c|}{200 m kurbağalama yüzme yarı final } \\
\hline Negatif siralar & 4 & 7.00 & 28.00 & \multirow{3}{*}{-1.817} & \multirow{3}{*}{0.069} & 2 & 2.00 & 4.00 & \multirow{3}{*}{-3.309} & \multirow{3}{*}{0.001} \\
\hline Pozitif sıralar & 15 & 8.36 & 92.00 & & & 14 & 9.43 & 132.00 & & \\
\hline Eşit & 0 & & & & & 0 & & & & \\
\hline \multicolumn{11}{|c|}{200 m kurbağalama yüzme final } \\
\hline Negatif siralar & 4 & 4.50 & 18.00 & \multirow{3}{*}{0.000} & \multirow{3}{*}{1.000} & 1 & 7.00 & 7.00 & \multirow{3}{*}{-1.540} & \multirow{3}{*}{0.123} \\
\hline Pozitif sıralar & 4 & 4.50 & 18.00 & & & 7 & 4.14 & 29.00 & & \\
\hline Eşit & 0 & & & & & 0 & & & & \\
\hline
\end{tabular}

Tablo 3 incelendiğinde kadınlar ve erkekler $200 \mathrm{~m}$ kurbağalama yüzme sonuçları ile aynı sporcuların olimpiyat oyunlarına katılma hakkı dereceleri incelendiğinde sadece erkek sporcuların eleme ve yarı final, kadın sporcuların ise eleme sonuçlarında anlamlı fark bulunmuştur $(p<0.01)$. Ortaya çıkan bu farkın çoğu sporcunun katılma hakkı derecelerine göre olimpiyat oyunlarında daha yavaş yüzmelerinden kaynaklandığı anlaşılmıştır (Tablo 3).

Tablo 4. Yüzücülerin olimpiyata katılma hakkı dereceleri ile yarışma sonuçları farkının cinsiyete göre karşıllaştırması

\begin{tabular}{|c|c|c|c|c|c|c|c|c|}
\hline Değişken & $\mathbf{n}$ & $\begin{array}{l}\text { Sira } \\
\text { ort. }\end{array}$ & $\mathbf{U}$ & $\mathbf{p}$ & $\mathbf{n}$ & Sira ort. & $\mathbf{U}$ & $\mathbf{p}$ \\
\hline & \multicolumn{4}{|c|}{$100 \mathrm{~m}$ Eleme } & \multicolumn{4}{|c|}{200 m Eleme } \\
\hline Kadın & 43 & 45.52 & \multirow{2}{*}{1009.500} & \multirow{2}{*}{0.994} & 31 & 33.76 & \multirow{2}{*}{550.500} & \multirow{2}{*}{0.523} \\
\hline Erkek & 47 & 45.48 & & & 39 & 36.88 & & \\
\hline & \multicolumn{4}{|c|}{$100 \mathrm{~m}$ Yarı final } & \multicolumn{4}{|c|}{$200 \mathrm{~m}$ Yarı final } \\
\hline Kadın & 16 & 16.66 & \multirow{2}{*}{125.500} & \multirow{2}{*}{0.926} & 15 & 15.27 & \multirow{2}{*}{109.000} & \multirow{2}{*}{0.682} \\
\hline Erkek & 16 & 16.34 & & & 16 & 16.69 & & \\
\hline & \multicolumn{4}{|c|}{$100 \mathrm{~m}$ Final } & \multicolumn{4}{|c|}{$200 \mathrm{~m}$ Final } \\
\hline Kadın & 8 & 7.88 & 27.000 & 0645 & 8 & 7.75 & 26.000 & 0.574 \\
\hline
\end{tabular}

Tablo 4 incelendiğinde, tüm kurbağalama kategorilerinde sporcuların olimpiyat oyunlarına katılma hakkı dereceleri ile yarışma sonuç dereceleri arasındaki farklar belirlenmiştir. Eleme, yarı final ve final için yapılan bu çalışmada aynı mesafe yarışmaları kadın ve erkek sporcu özelinde istatistiksel olarak karşılaştırılmıştır (Tablo 4). Yapılan analize göre yüzme derecesi farklarının cinsiyet değişkenine göre benzer olduğu bulunmuştur ( $\mathrm{p}>0.05)$.

\section{TARTIŞMA VE SONUÇ}

Kurbağalama yüzme yarışma sonuçlarının dereceleriyle ilgili pek çok analiz yapılmaktadır. Bu analizlerle, farklı yarışma ve mesafeye göre sporcuların performansları incelenerek yeni antrenman programlarının hazırlandığı belirtilmektedir. 2019 Dünya Yüzme Şampiyonası erkekler $100 \mathrm{~m}$ kurbağalama yüzme yarışma sonuçları split (dönüş) zamanı farkları açısından analiz edilmiştir. Sporcuların yarı final ve final performansları arasındaki ilişki istatistiksel olarak karşılaştırılmıştır. 
İncelenen 100 m kurbağalama yüzme yarışmalarında diskalifiye olmuş sporcular karşılaştırmaya dahil edilmemiştir. 100 m yarışmasının son 50 metresinde teknik ve hız açısından iyi olan yüzücülerin daha iyi yarışma derecesi elde edebileceği anlaşılmıştır (Vasic et al., 2021). Erkekler $100 \mathrm{~m}$ kurbağalama yüzme yarışması üzerine yapılan diğer bir çalışmada ise koordinasyon, itme ve toparlanma fazları incelenmiştir. Uygulanan yüzme testinde $100 \mathrm{~m}$ kurbağalama yüzme dereceleri alınırken su altı video kamera çekimleri yapılmıştır. Yüzücülerin kurbağalama yüzme hareket döngülerinde kolların göğüs hizasından uzatma yeteneğinin en iyi sonuçları verdiği ifade edilmiştir. Ek olarak daha yetenekli yüzücülerin aktif sürtünmeyi en aza indirmeyi başardığı açıklanmıştır (Strzała et al., 2014).

İsviçreli yüzücülerin 2006-2010 yılları arasındaki kurbağalama yüzme dereceleri ile FINA dünya şampiyonalarının 2003-2011 yılları arasındaki kurbağalama yüzme dereceleri karşılaştırılmıştır. Yüzme dereceleri analiz edilen sporcuların cinsiyet ve yaş değerleri de incelenmiştir. İsviçre'nin ulusal seviyedeki yüzücülerinde, yüzme hızındaki cinsiyete bağlı farklılıkların kurbağalamadan çok serbest stilde daha büyük olduğu ancak uluslararası düzeydeki FINA dünya şampiyonası finalist yüzücülerinde bu farklılığın olmadığı anlaşılmıştır. Hem kadın hem de erkek yüzücülerin serbest stile göre kurbağalama yüzmede daha genç yaşlarda en yüksek yüzme hızlarına ulaştığı ifade edilmiştir (Wolfrum et al., 2013).

Tüm yüzme stillerinde olduğu gibi kurbağalama yüzme tekniğinin doğru şekilde öğretilmesi yüzücülerin hızlarının artmasına katkı sağlamaktadır. Bu amaçla mobil cihazların yüzme öğrenme programlarında kullanılmasının eğiticiler için faydalı olacağı ifade edilmiştir (Scurati et al., 2019). Hołub ve arkadaşlarının yaptığı çalışmada, 200 m kurbağalama yüzme sırasındaki metabolik, kinematik ve temporal değişkenlerin pozitif ve negatif ilerleme hızı incelenmiştir. Sporcuların yüzme dereceleriyle birlikte laktat, $\mathrm{VO}_{2 \text { maks, }}$ nabız ve algılanan egzersizi derecesi değişkenleri arasındaki ilişki analiz edilmiştir (Hołub et al., 2021). Erkek yüzücülerle yapılan çalışmada $50 \mathrm{~m}$ kurbağalama yüzme kritik hız, yüzme ile yorgunluk arasındaki hiperbolik ilişki, maksimum anaerobik güç ve yüzme dereceleri ile aynı mesafenin dünya rekoru dereceleri arasında analizler yapılmıştır. Araştırmada yer alan sporculardan altı tanesinin ana branşının kurbağalama yüzme, diğer beş sporcunun ise ana branşlarının kelebek veya serbest yüzme olduğu ifade edilmiştir (Abe et al., 2006). Araştırmamızda sadece yüzme derecelerinin analizleri yapılıp sporcuların fizyolojik veya biyomekanik ölçümlerinin yapılamaması çalışmanın sınırlılıklarından biri olarak ortaya çıkmıştır. Araştırmadaki bir diğer sınırlılığımız ise sadece Tokyo 2020 Olimpiyat Oyunlarındaki kurbağalama yüzme yarışmalarının incelenmesidir. Araştırmamıza serbest, sırtüstü, kelebek, bireysel karışık ve bayrak yarışları dahil edilmemiştir.

Elit sporcuların kurbağalamada hız, ayak vuruş oranı ve ayak vuruş mesafesi değişkenlerine göre incelenmiştir. Uzun kulvar yapısındaki olimpik yüzme havuzunda yapılmış olan $100 \mathrm{~m}$ kurbağalama yüzme performansları analiz edilmiştir. Yarışma analizleri FINA'nın resmî sonuçlarından temin edilmiştir (Fritzdorf et al., 2009). 2000 Sidney Olimpiyat Oyunları'nın erkekler 200 m kurbağalama yüzme yarı final ve final performanslarının analiz edildiği çalışmada, yarışma sonuçları madalya alan 3 sporcu, madalya alamayan finalist 5 sporcu ve yarı final yüzüp elenen 8 sporcu olacak şekilde sınıflandırılmıştır. Yarışma sonuçları istatistiksel biçimde bu gruplara uygun olarak analiz edilmiştir (Chatard et al., 2001). Araştırmamız kapsamında incelenen yarışma sonuçları benzer türdeki çalışmalarda olduğu gibi resmî belgelerden temin edilmiştir. Bazı çalışmalarda olduğu gibi bu araştırmada da ana verilerin sporcuların yüzme dereceleri oluşturmuştur. Bu şekilde sporcuların performansları karşılaştırılabilir veriler haline gelmiştir.

Resmî sonuçların istatistiksel analizler için her yarışma kategorisinin finalde 1. olan sporcunun, finalde 8. olan sporcunun ve finalde yer alan toplam 8 sporcunun ortalama dereceleri alınmıştır. Kadın ve erkek sporcuların $100 \mathrm{~m}$ kurbağalama yüzme yarışmaları için 1968 Meksiko Olimpiyat 
Oyunları'ndan 2020 yılında kadar yapılmış toplam 13 final yarışmasındaki dereceler analiz edilmiştir. Aynı şekilde kadın ve erkek sporcuların 200 m kurbağalama yüzme yarışmaları için 1908 Londra Olimpiyat Oyunları'ndan 2020 yılına kadar yapılmış toplam 25 final yarışması dereceleri analiz edilmiştir (Hołub et al., 2021). Eleme, yarı final ve final olarak sınıflandırdığımız yarışma sonuçları ayrı ayrı analiz edilmiştir. Yarışma sisteminden kaynaklı olarak finallerde 8 sporcu, yarı finallerde 16 sporcu yarışmaktadır. Bu nedenle eleme ve yarı finallere göre finallerde daha az sayıda yüzme derecesi analiz edilmiştir (Tablo 2 ve Tablo 3). Eleme ve yarı final istatistik sonuçlarından farklı olarak final yüzme derecelerinde anlamlı farklılıkların oluşmadığı bulunmuştur ( $\mathrm{p}>0.05)$.

Hołub et al., (2021) yaptıkları bu araştırmaya göre 2021 yılında yapılacak olan Tokyo 2020 Olimpiyat Oyunları'nda yüzülecek kurbağalama yüzme dereceleri tahmin etmiştir. Çalışma sonucunda kadınlar $100 \mathrm{~m}$ final birincisinin 1:03:41 ve final sekizincisinin 1:05:65 saniyede yüzeceği, final ortalama derecesinin ise 1:04:44 olacağı ön görülmüştür. Aynı şekilde erkekler $100 \mathrm{~m}$ kurbağalama yüzmede final birincisinin 0:56:96 ve final sekizincisinin 0:59:16 saniyede yüzeceği, final ortalama derecesinin ise 0:58:12 olmasının mümkün olacağı tahmin edilmiştir (Hołub et al., 2021). Kadınlar 200 m kurbağalama yüzmede final birincisinin 2:15:75 ve final sekizincisinin 2:20:12 saniyede yüzeceği, final ortalama derecesinin ise 2:17:99 olacağı ön görülmüştür. Erkeklerde $200 \mathrm{~m}$ kurbağalama yüzmede final birincisinin 2:04:80 ve final sekizincisinin 2:06:12 saniyede yüzeceği, final ortalama derecesinin ise 2:05:10 olmasının mümkün olacağı tahmin edilmiştir (Hołub et al., 2021). Hazırlanan bu araştırma kapsamında incelenen Tokyo 2020 Olimpiyat Oyunları kurbağalama yüzme derecelerine göre kadınlar $100 \mathrm{~m}$ final birincisi 1:04.95, final sekizincisi 1:06.94, erkekler $100 \mathrm{~m}$ final birincisi 57.37, final sekizincisi 59.36 yüzmüştür. Final yarışma sonuçlarına göre kadınlar $200 \mathrm{~m}$ kurbağalama yüzme final birincisi 2:18.95, final sekizincisi 2:24.57, erkekler 200 metrede ise final birincisi 2:06.38, final sekizincisi 2:08.88 yüzmüştür. Bu sonuçlara göre, Hołub et al., (2021) tüm kurbağalama yüzme tahmini derecelerin elde edilen derecelerden yüksek hızda öngörüldüğü anlaşılmıştır.

Bu araştırma sonucunda, Tokyo 2020 Yaz Olimpiyat Oyunları 100 m ve 200 m kurbağalama yüzme elemelerinde sporcuların olimpiyata katılma hakkı derecelerinden anlamlı düzeyde daha yavaş yüzdüğü görülmüştür. Aynı yarışların final aşamalarında ise sporcuların olimpiyata katılma hakkı derecelerine benzer hızda yüzdüğü anlaşılmıştır (Tablo 2 ve Tablo 3). Tokyo 2020'de yer alan kurbağalama yüzmenin her kategorisinde en fazla sporcu Avrupa kıtasından katılım göstermiştir (Figür 1). Kadın ve erkek yüzücülerin olimpiyata katılma hakkı aldığı derecelerle eleme, yarı final ve final yüzme dereleri farkının benzer olduğu bulunmuştur (Tablo 4). Böylece cinsiyet değişkenine göre Tokyo 2020 Yaz Olimpiyat Oyunları kurbağalama yüzmede olimpiyata katılma hakkı dereceleri ile olimpiyat yarışma sonucu dereceleri arasındaki hız farkının benzer olduğu söylenebilmektedir. Sporcuların kurbağalama yüzme performanslarının eleme, yarı final ve final aşamalarına göre analizlerinin yapılması için daha kapsamlı çalışmaların yapılması önerilmektedir.

\section{KAYNAKLAR}

Abe, D., Tokumaru, H., Niihata, S., Muraki, S., Fukuoka, Y., Usui, S., \& Yoshida, T. (2006). Assessment of ShortDistance Breaststroke Swimming Performance with Critical Velocity. Journal of Sports Science and Medicine, 5, 340-348.

Chatard, J.C., Caudal, N., Cossor, J., \& Mason, B. (2001). Specific Strategy for The Medallists Versus Finalists and Semi Finalists in The Men's 200 M Breaststroke at The Sydney Olympic Games. In ISBS-Conference Proceedings Archive, Biomechanics Symposia, 10-13.

FINA. (2017). FINA Swimming Rules. https://www.fina.org/swimming/rules

FINA. (2020). Qualification System - Games of The XXXII Olympiad - Tokyo 2020 International Swimming Federation (FINA) Swimming. https://resources.fina.org/fina/document/2021/01/21/43ab180c-a924-44f3- 
8331-a40ca5c99f44/final_-_2020_07_15_-_tokyo_2020_-_revised_qualification_system_-_swimming__eng.pdf

Fritzdorf, S.G., Hibbs, A., \& Kleshnev, V. (2009). Analysis of Speed, Stroke Rate, and Stroke Distance for WorldClass Breaststroke Swimming. Journal of Sports Sciences, 27(4), 373-378.

Hołub, M., Stanula, A., Baron, J., Głyk, W., Rosemann, T., \& Knechtle, B. (2021). Predicting Breaststroke and Butterfly Stroke Results in Swimming Based on Olympics History. International Journal of Environmental Research and Public Health, 18(6621), 1-12.

Jaszczak, M. (2011). The Influence of Lower Limb Movement on Upper Limb Movement Symmetry While Swimming The Breaststroke. Biology of Sport, 28(3), 208-211.

Karasar, N. (2020). Bilimsel Araştırma Yöntemi: Kavramlar İlkeler Teknikler. İkinci yazım. 36. Baskı. Nobel Akademik Yayıncılık Eğitim Danışmanlık Tic. Ltd. Şti. Ankara.

Mason, B., Patton, S., \& Newton, A. (1989). Propulsion in Breaststroke Swimming. In ISBS-Conference Proceedings Archive.

Scurati, R., Michielon, G., Signorini, G., \& Invernizzi, P.L. (2019). Towards a safe Aquatic Literacy: Teaching The Breaststroke Swimming with Mobile Devices' Support. A Preliminary Study. Journal of Physical Education and Sport, 298, 1999-2004.

Strzała, M., Krężałek, P., Kucia-Czyszczoń, K., Ostrowski, A., Stanula, A., Tyka, A.K., \& Sagalara, A. (2014). Coordination and Propulsion and Non-Propulsion Phases in 100 Meter Breaststroke Swimming. Acta of Bioengineering and Biomechanics, 16(4). 83-89.

Tokyo 2020. (2021). Men's $100 \mathrm{~m}$ Breaststroke. https://olympics.com/tokyo-2020/olympicgames/en/results/swimming/results-women-s-100m-breaststroke-fnl-000100-.htm

Tokyo 2020. (2021). Men's $200 \mathrm{~m}$ Breaststroke. https://olympics.com/tokyo-2020/olympicgames/en/results/swimming/results-women-s-200m-breaststroke-fnl-000100-.htm

Tokyo 2020. (2021). Women's $100 \mathrm{~m}$ Breaststroke. https://olympics.com/tokyo-2020/olympicgames/en/results/swimming/results-women-s-100m-breaststroke-fnl-000100-.htm

Tokyo 2020. (2021). Women's $200 \mathrm{~m}$ Breaststroke. https://olympics.com/tokyo-2020/olympicgames/en/results/swimming/results-women-s-200m-breaststroke-fnl-000100-.htm

Vasic, A., Djurovic, M., Madic, D., \& Okicic, T. (2021). Differences in Split Times Between The Elite Breaststroke Swimmers. Journal of Anthropology of Sport and Physical Education, 5(2), 9-11.

Wolfrum, M., Knechtle, B., Rüst, C.A., Rosemann, T., \& Lepers, R. (2013). Sex-Related Differences and Age of Peak Performance in Breaststroke Versus Freestyle Swimming. BMC Sports Science, Medicine and Rehabilitation, 5(29), 1-10. 